\title{
Specificities of Syntactic Movement in Early Speech
}

\author{
Elena Papadopoulou ${ }^{1,2}$ and Natalia Pavlou ${ }^{3}$ \\ ${ }^{1}$ University of Essex, ${ }^{2}$ University of Cyprus, ${ }^{3}$ University of Chicago \\ epapadb@gmail.com, nataliapavlou@gmail.com
}

\begin{abstract}
This paper discusses syntactic errors and strategies found in child speech in an attempt to outline the linguistic development in early speech. The focus lies on children's ungrammatical utterances appearing to violate the Pied-piping condition in D-linked wh-questions as these are found in two different elicitation methodologies. The violation of grammatical constraints, such as the one discussed, supports the role of Economy in languages with a relevant discussion on the syntactic dependencies involved. The study targets the understanding of Movement specificities in Greek Cypriot children in order to identify the errors in these structures and the specificities of the variety.
\end{abstract}

\section{Introduction}

This paper aims to investigate patterns of syntactic errors in the production of D-linked wh-questions in Cypriot Greek (henceforth, CG) based on two different elicitation experiments. The study of errors or non-target responses in child speech can reveal the development of language and more specifically the order of the acquisition of syntactic phenomena. In first language acquisition (L1), it is assumed that certain structures are late acquired either because of their syntactic or semantic complexity. The complexity involved in a structure is surely a determining factor for the toddler, but the errors produced in the process of acquiring that complexity can indicate children's simple understanding of syntax in their mastering of language.

With focus on a specific variety, Cypriot Greek, data were drawn from two different experiments (Papadopoulou 2013; Pavlou 2010b) at different times of testing, where children aged 2;8-6;11. participated. The specificities observed involved a series of similar patterns found in the acquisition of D-linked questions, which are syntactically assumed to show pied-piping (Ross 1967), as indicated in (1) below:

\section{(cc) BY-NC-ND}



(1) [Inda milon] kofki I kopela? which apple.ACC cutting.3SG the.NOM girl.NOM 'Which apple is the girl cutting?'

Following the different errors and non-target responses observed in the two experiments, we argue that these are syntactically-motivated patterns, which are driven by syntactic reasons and thus appear even at 6 years old (henceforth, yr) children.

In this paper, we aim to briefly discuss the background literature with regard to errors found in the acquisition of $\mathrm{D}$-linked ${ }^{1}$ questions in several languages in order to list the different error patterns involved. In Section 2, we will give an overview of wh-questions and their formation in Cypriot Greek. Data were drawn from a syntactic priming experiment, presented in Section 3 and an elicitation task, presented in Section 4. Section 5 focuses on decomposing the errors observed in the experiments and providing an explanation that supports Economy in syntax and illustrates a clearer picture for specificities in early speech. By illustrating the different examples of errors appearing in the data, we will provide a theoretical analysis by adopting the Immediate Move Hypothesis (Pavlou 2012).

\subsection{Background Literature}

To start with, pied-piping in D-linked questions is generally assumed to involve a wh-word, which is a determiner that moves to the target position and piedpipes the NP along with it, see (1) above. The study of pied-piping (Ross 1967) in D-linked questions and other structures has been a matter of many studies (Butler \& Mathieu 2005; Cable 2008; Fanselow \& Cavar 2002; Heck 2008; Mathieu 2002 among others) for decades with focus on the optionality or not of pied-piping in certain languages such as French, as in (2) below.

(2a) Combien as-tu lu de livres? how-many have-you read.2SG of books

'How many books have you read?'

(2b) Combien delivres as-tu lu?

how-many of books have-you read.2SG

'How many books have you read?'

1 These questions are also called Referential, because they refer to the binding chain of the referred NP with the wh-word. 
A recent acquisition study of ninety pre-school children $(4 ; 0-7 ; 0)$ in Standard Modern Greek (SMG) reported error findings related to sub-extraction of whphrases (Asproudi 2011). Asproudi reports that sub-extraction of wh-phrases was the most frequent technique and argues that these are in line with Dutch data (van Kampen 1997). In her conclusions, she argues that the morphological richness of SMG is a key factor to the possibility of sub-extraction of wh-phrases in child speech.

Stavrakaki (2006) after testing 8 SLI children with 2 control children for each one tested, argues that even though children acquired the formation of whquestions by age 4, they still produced errors. First, this study indicates that there was frequent omission of the NP in D-linked subject and object questions. According to Stavrakaki, these errors may have been the consequence of the phonological similarity between pjos 'which' and pjos 'who'. Second, SLI children showed a tendency of converting a non-D-linked question into D-linked question or a non-D-linked who-object question into a D-linked which-object question. Most importantly, this study reports gap-filling errors², which are characterized by splitting of the wh-phrase and the NP (3). Stavrakaki concludes that the interpretation of $D$-linked questions requires the discourse linking with the NP and the costly simultaneous participation of syntactic and discourse-relevant operations (Avrutin 2000).

(3) (SLI response)

*O andras pion htipise ton pieiko?

the.NOM man.NOM which hit.3SG the.ACC monkey.ACC

'Which monkey did the man hit?

(Stavrakaki 2006 p. 390)

Van Kampen (1994, 1996 and subsequent work) argues for a PF/LF discrepancy in child language (see van Kampen 1996 for a detailed discussion) when children produce this kind of wh-subextraction errors in (3). In her analysis, $X^{\prime}$ raising is triggered by morphological greed or by a PF adjacency condition. This kind of movement is proposed to have a direct link with the satisfying of any PF needs as in (4).

(4) "welke wil jij [twh liedje] zingen?

(Sarah 3;7)

which want you song sing?

'[Welk liedje $]_{D P}$ wil jij $t_{D P}$ zingen?'

(Adult/later child Dutch)

'Which song want you sing?'

(van Kampen 1996)

$\mathbf{2}$ For consistency matters, we refer to this term as wh-subextraction. 
It should be noted that Nomura and Himoru (2005) showed in their study with 15 Japanese-speaking children $(4 ; 4-5 ; 2)$ that, unlike Dutch (van Kampen 1997) and English (Chen et al. 1998), their participants did not violate the Piedpiping condition (Ross 1967).

Catalan (Gavarró \& Solà 2004a; Gavarró \& Solà 2004b) is another language showing wh-subextraction errors in the acquisition of pied-piping in D-linked questions. Gavarró \& Solà (2004) argue that errors, such as sub-extractions in child speech are explained by Kayne's (2002) remnant movement, which is determined by Case requirements.

Last, Roeper and Perez-Leroux (1997) discuss the interpretation of questions by children (Schaeffer 1991) expressing lack of movement of the NP in D-linked questions. For example, wh-subextraction errors appear in wh-possessor questions (also see Gavruseva \& Thornton 2001; Thornton \& Gavruseva 1996) as in (5) below.

(5):* Whose did you see book

'Whose book did you see?'

Wh ['s book]

(Roeper \& Perez-Leroux 1997 p.16)

As they explain, "the morphological constituency is altered by the phonological creation of a single word whose" (p.16) and this causes the need for pied-piping.

It appears that errors in the acquisition of pied-piping are met often in several child languages. To sum up, consider Table 1 below:

Table 1.

Studies that report errors in the acquisition of D-linked questions

\begin{tabular}{|l|l|l|}
\hline \multirow{2}{*}{ SMG } & Asproudi 2011 & Sub-extraction of whs \\
\cline { 2 - 3 } & Stavrakaki 2006 & Sub-extraction of whs, NP omission \\
\hline Dutch & van Kampen 1997 & Sub-extraction of whs \\
\hline Japanese & Nomura \& Himoru 2005 & No errors \\
\hline Catalan & Gavarró \& Solà 2004 & Sub-extraction of whs \\
\hline English & Gavruseva \& Thornton 2001 & Sub-extraction of possessors \\
\hline
\end{tabular}

The specificities found in the acquisition of D-linked questions appear in different languages that follow different grammatical rules and different structures. We will not elaborate further on the differences between the languages presented above, as our focus is on Cypriot Greek. We turn in the next section to examine the syntactic distribution of questions in CG. 


\section{Wh-questions in CG}

In this paper, we explore only one type of question, namely, the D-linked (or Referential) pco/inda/ti 'which' question ((6) below).

(6)

$\begin{array}{llll}\text { Pco /Inda vivlio } \quad \text { @kyavazi } & 0 & \text { andras? } \\ \text { which book.ACC reading.3SG } & \text { the.NOM } & \text { man.NOM } \\ \text { 'Which book is the man reading?' } & & \end{array}$

With regard to CG question formation, this shows morphological resemblance to SMG with minor pragmatic-semantic and morpho-phonological differences (Newton 1972) as well as substantial formation differences with respect to the embu 'is-it-that' strategy and inda mbu 'what/why' wh-phrases.

Inda 'what/which' is invariant in gender, number, and case and it is used either prenominally ('what/which NP') or pronominally (simple 'what'). For a summary of the SMG and CG wh-phrases, consider the Table below:

Table 2.

Wh-phrases in CG and SMG (Pavlou 2012)

\begin{tabular}{|c|c|c|}
\hline SMG & CG & Meaning \\
\hline pios/pjos & pcos & ,who' \\
\hline$t i$ & ti/inda $m b u^{5}$ & ,where' \\
\hline$p u$ & $p u$ & ,when' \\
\hline pote & pote & ,how much' \\
\hline poso & poso(n) & ,why' \\
\hline jati & jati/inda/ inda $m b u$ & ,how' \\
\hline pos & pos/indalo(i)s & ,from where' \\
\hline (apo $p u)$ & pothen &
\end{tabular}

An example of inda 'what' in D-linked questions is given below. Pied-piping in D-linked questions is not optional and it is characterized by movement of the noun along with the operator (7).

3 Pavlou (2010a), contra to Papadopoulou (2013) argues that inda mbu has a complex syntax with inda being the wh-phrase and mbu being on $\mathrm{C}$, following the discussion in Grohmann et al. (2006).

4 When inda 'what' is adjoined to embu 'is-it-that', resulting in indambu 'what is-it-that' (Papadopoulou 2013) or inda mbu (Pavlou 2010a) four other allomorphs are identified, namely innambu, nambu, tambu and ambu (Pavlou 2010a).

5 Inda mbu is sometimes treated as a single element, depending on the analysis assumed (see Pavlou 2010a; Papadopoulou 2013). 
(7) Inda milon troi i kopela?

which apple.ACC eating.3SG the.NOM woman.NOM

'Which apple is the woman eating?'

Grohmann and Papadopoulou (2010) note that inda 'why' cannot remain insitu and always need to be fronted (8a), but inda 'what' in a complex wh-phrase can be found in-situ (8b).

(8a) Inda vivlion $\theta$ kiavazi o Nikos?

which book.ACC reading.3SG the.NOM Nick.NOM

'Which book is Nick reading?'

(8b) 0 Nikos $\theta$ kiavazi inda vivlion?

the.NOM Nick.NOM reading.3SG which book.ACC

'Nick is reading which book?'

Split-DPs in complex wh-phrases, or better split wh-constructions, were allowed in Classical Greek as presented in Mathieu and Sitaridou (2005). At that time, wh-elements did not need to raise together with the relevant nominal. These structures appear with the use of tis 'his/hers', which was inflected for $\varphi$-features. Today, the possibility for split-constructions as shown in SMG appears only in wh-constructions that involve a possessor marked with genitive Case (Table 3) (also examples (9a) \& (9b) below).

Table 3

Wh-phrases that allow(ed) Split-DPs (Pavlou 2012)

\begin{tabular}{|c|c|c|c|}
\hline Classical Greek & SMG & CG & Meaning \\
\hline tis-tina-tis & $t i$ & $t i$ & ,what' \\
\hline & tinos $_{\text {Poss }}$ & tinos $_{\text {Poss }}$ & ,whose' \\
\hline & Pianu/Pjanu $_{\text {poss }}$ & PCu & 'woss \\
\hline
\end{tabular}

CG does not allow any split-DPs in wh-constructions except in the case that a possessor element is involved. Tinos 'whose' appears in Split wh-constructions today in both SMG and CG, but as Pavlou (2012) argues Greek Cypriot speakers disallow the possession reading, when there is a possibility of a second reading. The second reading is the one which specifies the possessor wh-phrase as the indirect object of a ditransitive verb. The availability of sub-extraction from a tinos-phrase, with no change in meaning can be seen in (9b) for SMG. When tinos is separated from to vivlio, as in (9b), the same interpretation is possible. Even though CG also employs tinos-phrases, when the reading in (10) is available, the reading corresponding to (9b) becomes unavailable. 
(9a) Tinos to vivlio eferes? whose.GEN the.ACC book.ACC brought.2SG

(9b) Tinos eferes to vivlio? whose.GEN brought.2SG the.ACC book.ACC 'Whose book did you bring?'

(10a) Tinos to VIVlio eferes? whose.GEN the.ACC book.ACC brought.2SG "Whose book did you bring"

(10b)Tinos eferes to vivlio? to whom.ACC brought.2SG the.ACC book.ACC 'To whom did you bring the book?'

(Pavlou 2012)

Cypriot Greek does not allow any Split-DPs in questions in adult speech, so children are expected not to show any patterns of split wh-constructions in their acquisition of questions. We will consider relevant cases in the first experiment discussed in the next section.

\section{Syntactic Priming in CG}

\subsection{Syntactic Priming Experiment in Cypriot Greek}

A Syntactic Priming Experiment in Cypriot Greek (SPE-CG) (Papadopoulou 2013) was conducted with a hundred three monolingual native speakers-children of CG, aged 2;8 - 6;5. All children participating in the experiment attended kindergartens around the area of Larnaca and Limassol district. After being randomly selected, they were distributed in three age groups (Table 4 below).

Table 4.

SPE-CG participants

\begin{tabular}{|c|c|c|c|c|}
\hline Age group & Age range & Number of participants & Mean age & Standard deviation \\
\hline AG1 & $2 ; 8-3 ; 11$ & 22 & $3 ; 4$ & 3 months \\
\hline AG2 & $4 ; 0-4 ; 11$ & 26 & $4 ; 3$ & 2 months \\
\hline AG3 & $5 ; 0-6 ; 5$ & 45 & $5 ; 7$ & 3 months \\
\hline
\end{tabular}

\subsection{Material and Procedure}

The experiment involved thirty sentences of a prime $(P)$ and a target $(T)$, with a different verb, agent and patient for each $\mathrm{P}$ and $\mathrm{T}$. Three wh-words were tested, 
namely, pco 'which' D-linked, ti 'what' non D-linked and the dialectal element inda 'which' D-linked, each in 10 sentences. Test sentences were distributed across the topicalization or not of the subject and appearance of embu 'is-itthat' following (11) and (12) below respectively; which in accordance with the appearance or not of embu 'is-it-that' result in four main conditions which were distributed between groups.

$\begin{array}{lllll}\text { O andras pCo vivlio } & \text { (embu) } & \text { Okyavazi? } \\ \text { the.NOM man.NOM which book.ACC } & \text { (is-it-that) reading.3SG } \\ \text { 'Which book is the man reading?' } & & \end{array}$
Pco vivlio
(embu)
Okyavaz
o andras?
which book.ACC (is-it-that) reading.3SG the.NOM man.NOM
'Which book is the man reading?'

\subsection{Results}

Due to full pushing for priming children did not deviate much from the expected priming questions, even at a very young age. Raw numbers are found in Table 5 below.

Table 5.

SPE-CG raw numbers

\begin{tabular}{|c|c|c|c|c|c|c|}
\hline Prime & \multicolumn{3}{|c|}{$W h+V+$ Subj } & \multicolumn{3}{|c|}{ Subj $+W h+V$} \\
\hline Target & $\begin{array}{c}\text { Wh + V + } \\
\quad \text { Subj }\end{array}$ & $\begin{array}{c}\text { Subj + Wh } \\
+V\end{array}$ & Ungrammatical & $\begin{array}{c}\text { Wh + V + } \\
\text { Subj }\end{array}$ & $\begin{array}{c}\text { Subj + Wh } \\
+V\end{array}$ & Ungrammatical \\
\hline \multirow{2}{*}{ AG1 } & \multicolumn{2}{|c|}{135} & \multirow{2}{*}{2} & \multicolumn{2}{|c|}{170} & \multirow{2}{*}{1} \\
\hline & 133 & - & & 88 & 81 & \\
\hline \multirow{2}{*}{ AG2 } & \multicolumn{2}{|c|}{155} & \multirow{2}{*}{4} & \multicolumn{2}{|c|}{200} & \multirow{2}{*}{6} \\
\hline & 151 & - & & 28 & 168 & \\
\hline \multirow{2}{*}{ AG3 } & \multicolumn{2}{|c|}{345} & \multirow{2}{*}{1} & \multicolumn{2}{|c|}{330} & \multirow{2}{*}{-} \\
\hline & 334 & - & & 10 & 320 & \\
\hline
\end{tabular}

As depicted in Figure (1) below children perform at almost 100\% when they are primed with the word order ' $\mathrm{Wh}+\mathrm{V}+\mathrm{Subj}$ '. AG3 performs the same irrespective of the word order condition provided (Figures 1 and 2). In contrast AG2 seems to perform slightly less (84\%) when they are given the topicalized word order as prime 'Subj + Wh + V'. The younger group (AG1) seems to have great difficulty with the topicalized word order condition. They (AG1) performed at $47 \%$ following the target word order and reversed to the non-topicalized word order at $52 \%$ of the cases. 


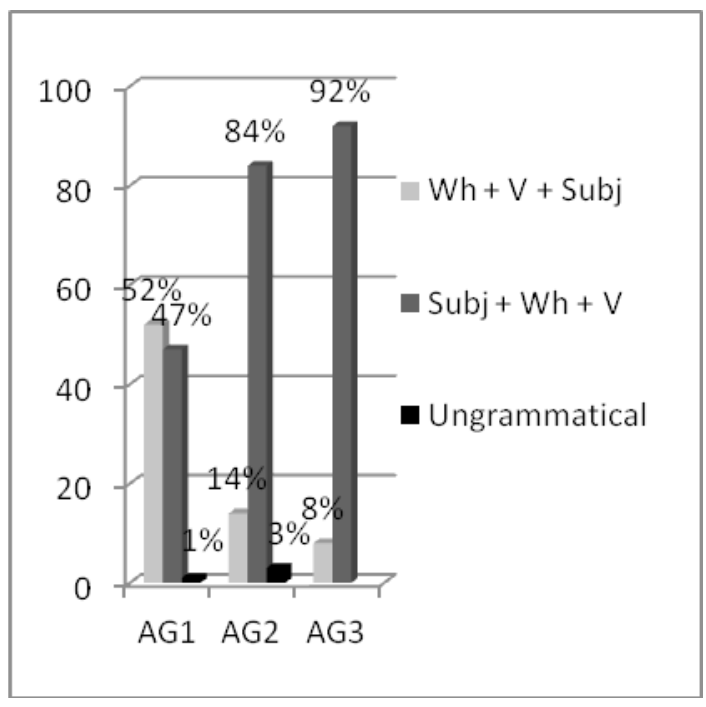

Figure 1. SPE-CG $W h+V+S u b j$ results

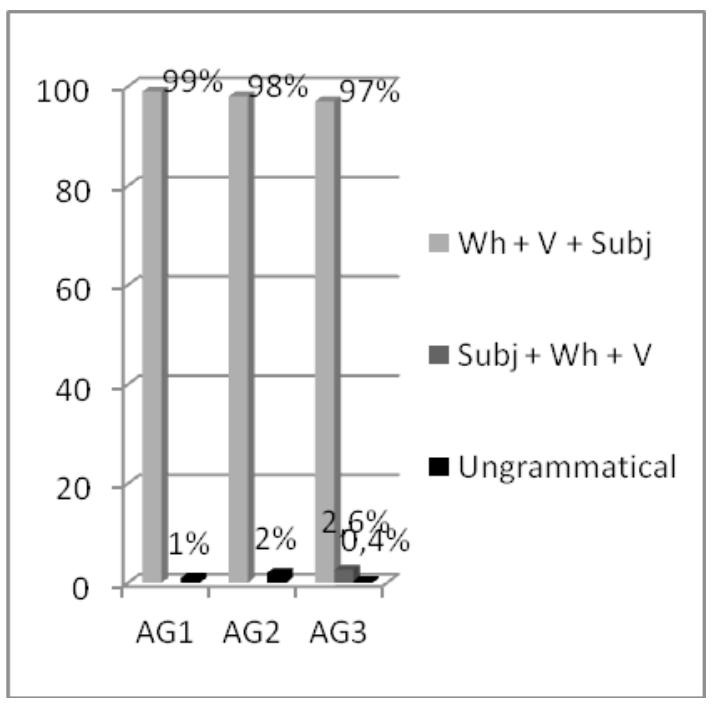

Figure 2. SPE-CG Subj+Wh+V results

Concentrating on specificities of syntactic movement in early speech failing to be primed by the topicalized word order condition suggests possible difficulties to move the subject at a topic position for AG1 (see inter allies Papadopoulou 2013), Papadopoulou \& Pavlou 2012). Results above do not refer to the priming 
effects or not of embu 'is-it-that', since it was not highly primed and its priming-or not- was not related to syntactic movement difficulties, given that it is generated at Spec-CP hence, not moved at that position (see again Papadopoulou 2013 for an in depth investigation).

Overall, children across all age groups made a few ungrammatical errors, failing to obey the primed word order (5.1\% across age groups). The majority of the errors made referred to the inability to obey pied-piping conditions resulting in a split DP with the wh-word correctly moved to Spec-CP but, with the noun remaining VP-internally resulting in examples like (13) instead of providing the supposed target (14) below. $^{6}$

(13) *Pco kaӨarizi I kopela pcato?

which cleaning.3SG the.NOM girl.NOM plate.ACC

'Which plate is the girl cleaning?'

(14) Pco pcato kaӨarizi I kopela?

which plate.ACC cleaning.3SG the.NOM girl.NOM

'Which plate is the girl cleaning?'

Children have also produced sentences with both the wh-object phrases and the overt object by moving on the one hand the wh-word to Spec, CP but at the same time pronouncing the NP in the VP as in $(15)^{7}$ below rather than (16).

(15) *O andras ti anizi goro?

the.NOM man.NOM what opening.3SG present.ACC

'Which present is the man opening?'

(16) 0 andras ti anizi?

the.NOM man.NOM what opening.3SG

'What is the man opening?'

Even though these utterances are limited in number, a greater number of these errors are found in the Guess What Game discussed in the next section.

The Guess What Game

Similarly to SPE-CG, data were collected from Greek Cypriot children who were attending either public or private kindergartens in Limassol, the southern town in Cyprus. Participants were distributed in four age groups, as summarized in Table 6.

62 children aged 3;1 failed to obey pied piping condition twice and 4 more, aged 5;05, 4;11, $4 ; 0$ and $3 ; 7$, failed to obey the condition but also changed the wh-word in 8 instances

72 children aged 4;11 and 4;2 at 3 instances have produced wh-questions similar to the example given where wh/object doubling is observed. 
Table 6.

GWG participants

\begin{tabular}{|c|c|c|c|c|}
\hline Age group & Age range & Number of participants & Mean age & Standard deviation \\
\hline AG1 & $3 ; 0-3 ; 11$ & 19 & $3 ; 7$ & 3 months \\
\hline AG2 & $4 ; 0-4 ; 11$ & 22 & $4 ; 7$ & 3 months \\
\hline AG3 & $5 ; 0-5 ; 11$ & 22 & $5 ; 5$ & 3 months \\
\hline AG4 & $6 ; 0-6 ; 11$ & 18 & $6 ; 2$ & 1 month \\
\hline
\end{tabular}

\subsection{Material and Procedure}

The materials used were two puppets, a baby frog and a baby lion, so as to provide enthusiasm to the children. The procedure followed was the same for all children tested and each child was introduced to it individually. The researcher would introduce the child to the idea that they were going to play a game and the game was to collect chickens with baby lion and baby frog and see who can collect the most chicks. The one who would collect the most chicks would be the winner and would win a prize at the end. What the child needed to do was to ask a question about each picture shown. The child believes that $\mathrm{s} / \mathrm{he}$ is competing with the puppets, but by manipulating the way that the puppets respond, the child always wins the game.

The test had 24 items in six sections with each one investigating a different syntactic structure. In this paper, we will discuss the findings for block 4, which involved D-linked questions. Each set of test items was preceded by two warm up items. In the warm up items, the child simply copied the adult's questions but then $s /$ he was told that $s /$ he must go ahead to ask the questions directly. The same scenario was repeated for each set of items. An example, as used in Block 4, is provided below:

Warm-up 2: Inda aftokinitaki krata I korua? (Researcher) which car.ACC holding.3SG the girl.NOM

'Which car is the girl holding?'

$\begin{array}{ll}\text { Puppet: } & \text { En su milo esena. } \\ \text { (To research.) } & \text { not you.GEN talk.1SG you.ACC } \\ & \text { Pezo mono me mora. } \\ & \text { play.1SG only with children.ACC } \\ & \text { 'I am not talking to you. I only play with children'. }\end{array}$


Researcher: @ells na rotisis esi ton vatrahulin? (To child) want.2SG to ask.2SG you.NOM the.DET baby-frog.ACC 'Do you want to ask the baby frog?'

Child: Inda aftokinitaki krata I korua?

(To puppet) which car.ACC holding.3SG the.NOM girl.NOM

'Which car is the girl holding?'

Puppet: $\quad$ To kotzino.

(To child) 'The red one'.

Researcher: Ate, rota ton ya.

(To child) come on ask.2SG him.ACC for.PRE

tutin tin foto rafian.

this.DEM the.DET photograph.ACC

'Now, ask baby frog about this picture'.

Target 1: Inda ðoro anis o andras?

(Child) which present.ACC opening.3SG the.NOM man.NOM

'Which present is the man opening?'

(Pavlou 2012)

The child then produced other 3 more questions and the researcher repeated the same procedure for the next blocks.

\subsection{Results}

A control group with 10 adults also participated in the experiment and as expected, provided the target responses with a high percentage.

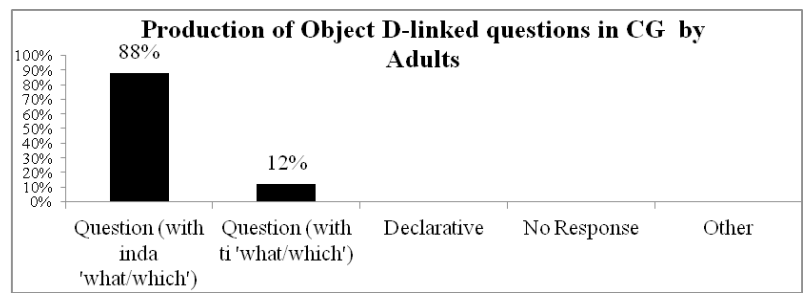

Figure 3. Production of Object D-linked questions in CG by Adults

Adults mostly produced inda-questions, following the target responses, but a relatively low percentage (12\%) responded with a non-target ti-question.

Overall, the successful production of 'which' questions was relatively poor with raw numbers found in Table 7 below and summarized in Figure 4. 
Table 7.

Production of Object D-linked questions in CG

\begin{tabular}{|c|c|c|c|c|c|}
\hline & inda 'what/which' & ti 'what/which' & Declarative & No Response & Other \\
\hline \multirow{2}{*}{$3 \mathrm{yr}$} & \multicolumn{2}{|c|}{39} & \multirow{2}{*}{16} & \multirow{2}{*}{4} & \multirow{2}{*}{17} \\
\hline & 4 & 35 & & & \\
\hline \multirow{2}{*}{$4 \mathrm{yr}$} & \multicolumn{2}{|c|}{50} & \multirow{2}{*}{25} & \multirow{2}{*}{0} & \multirow{2}{*}{13} \\
\hline & 0 & 50 & & & \\
\hline \multirow{2}{*}{$5 \mathrm{yr}$} & \multicolumn{2}{|c|}{60} & \multirow{2}{*}{8} & \multirow{2}{*}{0} & \multirow{2}{*}{20} \\
\hline & 2 & 58 & & & \\
\hline \multirow{2}{*}{$6 \mathrm{yr}$} & \multicolumn{2}{|c|}{47} & \multirow{2}{*}{0} & \multirow{2}{*}{0} & \multirow{2}{*}{25} \\
\hline & 7 & 40 & & & \\
\hline
\end{tabular}

D-linked questions had the lowest percentages in comparison with the elicitation of the other wh-questions in the experiment.

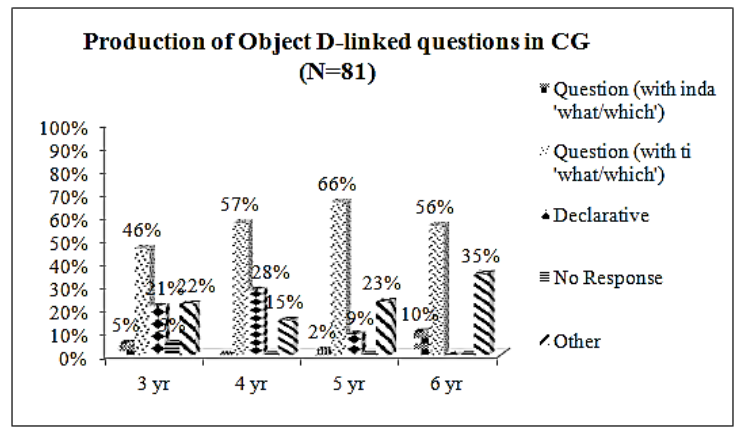

Figure 4. Production of D-linked questions: Overall results

Children performed very poorly in the successful production of target questions and showed a substantial preference for the CG-like wh-phrase ti 'what'. Very low percentages were observed for the production of questions with inda 'which' and this appears in the youngest group ( $3 \mathrm{yr}$ ) and the older groups (5 yr \& $6 \mathrm{yr}$ ).

The percentages shown in Figure 4 can be sub-divided into further categories as other sub-types were observed. These percentages do not just show the successful production of the pied-piped structure with a wh-phrase, but also production of a question with omission of the noun and ungrammatical questions characterized by lack of movement of the noun. 


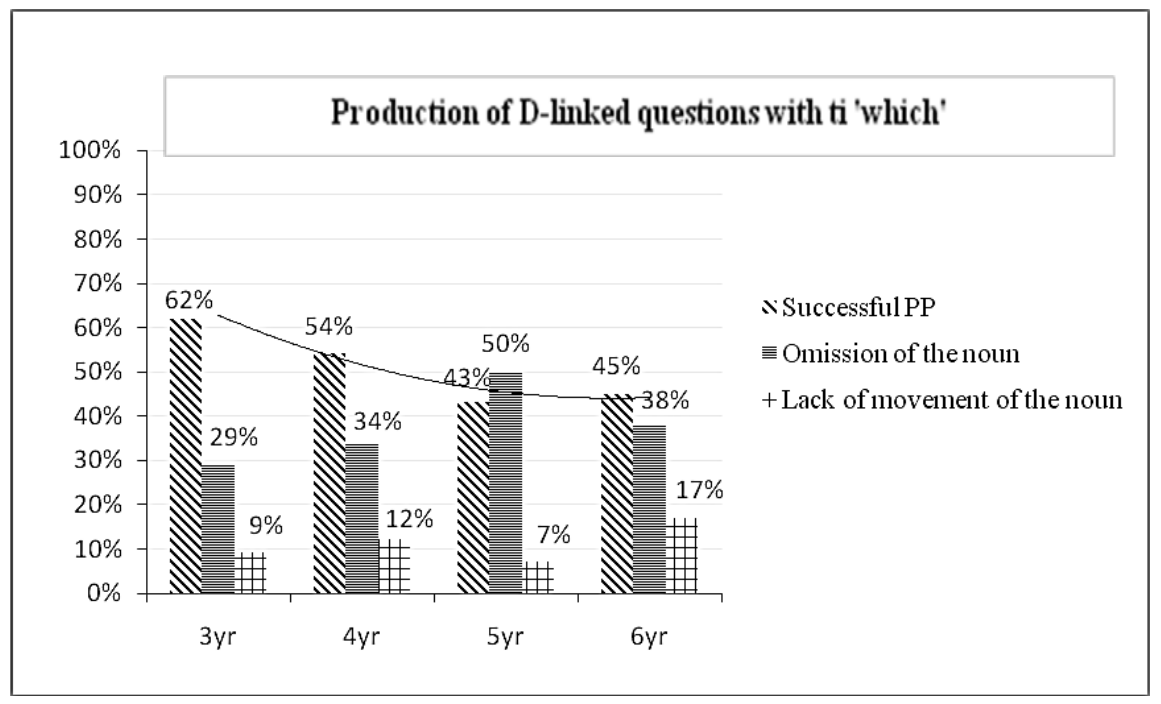

Figure 5. Sub-types of responses to D-linked questions

Figure 5 corresponds to the overall question production with $t i$ 'which'. Note that the successful pied-piping in wh-questions decreases by age. Very high percentages were observed with regard to the omission of NP from the D-linked question.

In addition, errors were also observed showing the predicted lack of movement of the noun phrase and sole movement of the operator. This kind of error appeared with both a stranded NP and a determiner + NP sequence, but most importantly it also appeared in complex wh-phrases of the type 'what colour car', as in (17).
*Ti ani $\mathrm{Ti} \quad$ kutin O andras?
which opening.3SG box.ACC the.NOM man.NOM

'Which box is the man opening?'
(18) $* \mathrm{Ti}$ hroma krata aftokinitaki o andras? which colour.ACC holding.3SG car.ACC the.NOM man.NOM 'What is the colour of the car that the man is holding?'

Figure 6 below shows responses from children when attempting to produce a question with inda 'which'. The breakdown of response patterns can be seen to differ substantially from the pattern seen in Figure 5. 


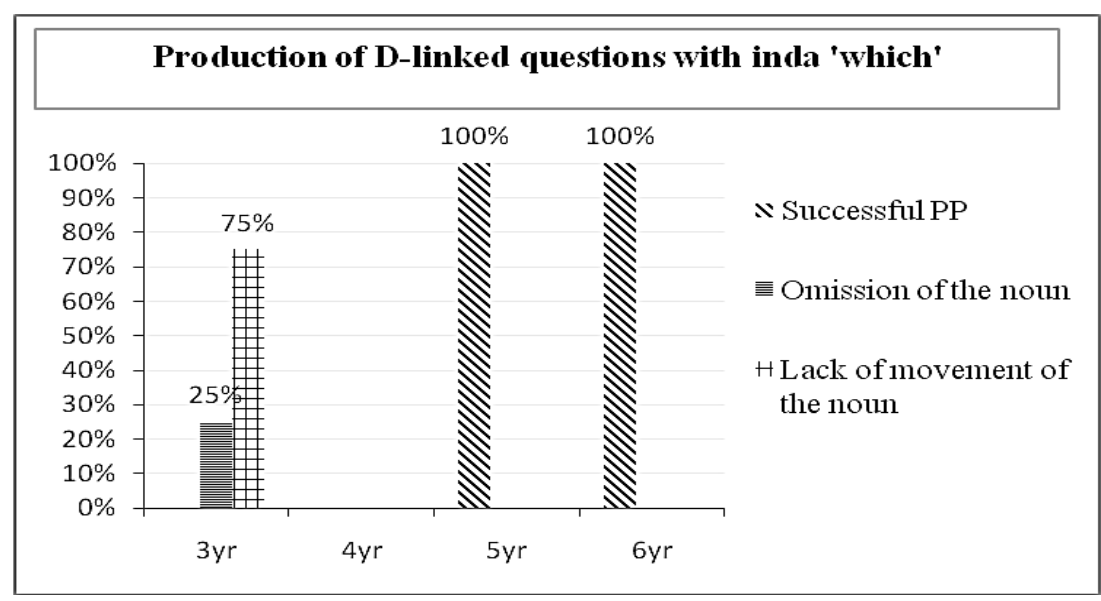

Figure 6. Successful pied-piping and errors with inda 'which' in Block 4

Even though there was no successful production of questions with the use of the Cypriot-specific inda 'which' in the $3 \mathrm{yr}$ and $4 \mathrm{yr}$ groups, the limited utterances of inda in $5 \mathrm{yr}$ olds and $6 \mathrm{yr}$ olds (see (19) and (20) below) show that the children performed at ceiling in any attempt made. The children exhibited target pied-piping of an NP with inda 'which' and formation of a D-linked whquestion.
"Inda fori
o andras
kaphelo?
which wearing.3SG the.NOM man.NOM hat.ACC
'Which hat is the man wearing?'
(20) *Inda hroma krata aftokinitakin o andras? which colour.ACC holding.3SG car.ACC the.NOM man.NOM 'What is the colour of the car that the man is holding?'

Errors in this case appear only in the $3 \mathrm{yr}$ old group, which is the youngest group and would expectedly show the greatest frequency of errors for a late-acquired structure.

\section{Discussion}

The types of errors produced by children and explored here involve a logical explanation under which fundamental notions, such as Economy, are expressed through different structures. Based on the data taken from the two experiments discussed above, children's errors in D-linked questions appear 
in similar ages and are not affected by any specific methodology. It is evident that full pushing for priming minimized errors but it did not prevent them. Our analysis supports that the errors are not speech errors, but innately-motivated patterns that follow a theoretical reasoning in syntax. Two experiments were discussed in order to outline similar patterns appearing in children production of D-linked questions. Children participating in a syntactic priming experiment produced a specific number of utterances showing sub-extraction of the whphrase from a complex wh-phrase. A similar type of errors was also found in an elicitation game targeting production of wh-questions in the same variety. In the same experiment, wh-subextraction was also found in strings of the type 'which colour car' by having the wh-phrase and the following NP moving the beginning of the sentence and stranding the second following NP. This contrastive study was aiming to show that the actually methodology does not play a very significant role, when a specific path of acquisition of a structure is involved. We have seen that errors appeared even when the participants were fully primed and should not have produced these. We should note, however, that there is a substantial difference in the number of errors appearing between the two experiments.

This type of errors is found cross-linguistically without following a strict path of acquisition. Several accounts have been proposed in order to account for these errors, but there was no agreement in the literature upon the phenomenon. As presented in Section 2, van Kampen (1994 and subsequent work) argues that there is a PF/LF discrepancy, whereas Gavarró \& Solà (2004) argue that there is involvement of remnant movement. For Greek, Stavrakaki (2006) has argued that the errors are a result of a phonological similarity of the wh-word with the wh-object question, but as these errors have appeared in other languages as well, this explanation cannot be valid. Asproudi (2011) refers to the morphological richness of the language, which can be a possibility since both Greek and Cypriot Greek are morphologically rich languages. This still however does not explain why these error patterns should occur.

These particular errors in child speech provide strong arguments for the Economy in language as well as its different applications on a theory of grammar. Simplicity, in other words, in language acquisition lies at the core of generative theory, as we try to represent a system which requires the minimum effort or procedure in all aspects of language.

We adopt the Immediate Move Hypothesis (Pavlou 2012), as outlined in (21), based on two crucial characteristics of the errors presented. Children move as little as they can in their production of D-linked questions, but as much as they need. This analysis predicts that when children produce these errors, $\mathrm{C}$ attracts the goal as follows: 
(21) Immediate Move Hypothesis

Move $\alpha$ iff:

a) $\alpha$ carries the target feature

b) $\alpha$ is immediately contained within the nearest to the probe maximal projection containing the target feature

c) No $\beta$ is contained in $\alpha$ such that $\beta$ immediately contains the target feature

d) If $\alpha$ forms an $X P$, then it must immediately contain the target feature

(Pavlou 2012)

In languages that do not allow split-DPs, C attracts as little as it can, while at the same time it is satisfying with it any of its needs, which are the uninterpretable features in C. In children's syntax, both conditions above apply separately. While they could move the first DPMAx that contains the relevant features to satisfy the condition 'Move as little as you can', they also apply 'Move as much as you need' and therefore ignore the presence of the shortest (in distance) outer DPMAX and move only the internal DPMAX as in (22) below where only the wh-word is moved.

(22) *Inda fori o andras kapelo? which wearing.3SG the man.NOM hat.ACC 'Which hat is the man wearing?'

To sum up, Immediate Move Hypothesis was proposed to account for subextraction phenomena in D-linked questions based on data from Cypriot Greek and other environments of similar type. To conclude, any generalizations defining these errors as speech errors, and not innately-motivated patterns, as suggested by Nomura and Hirotsu (2005), are not validated. 


\section{References}

Asproudi, E. 2011. Non-Target Long-Distance Wh-Questions. Crosslinguistic Typological Distinctions in Early L1 Production. Proceedings of the $20^{\text {th }}$ International Symposium on Theoretical and Applied Linguistics (ISTAL 20). Aristotle University of Thessaloniki, Thessaloniki 1-3 April.

Avrutin, S. 2000. Comprehension of Wh-questions by children and Broca's aphasics. In Y. Grodzinsky, L.P. Shapiro and D.A. Swinney, eds. Language and the brain: Representation and processing, San Diego: Academic Press, 295-312.

Butler, A. and E. Mathieu. 2005. Split-DPs, generalized EPP, and visibility. MIT Working Papers in Linguistics, 49, 49-57.

Cable, S. 2008. There is no such thing as Pied-Piping. Ms., MIT.

Chen, D., M. Yamane and W. Snyder. 1998. Children's left-branch violations: Evidence for a non-parametric account. 22nd Annual Boston University Conference on Language Development, Somerville, MA: Cascadilla Press.

Fanselow, G. and D. Cavar. 2002. Distributed Deletion. In A. Alexiadou, ed. Theoretical Approaches to Universals. Amsterdam, John Benjamins, 65-107.

Gavarró, A. and J. Solà. 2004a. Wh-subextraction in child Catalan. Second Lisbon Meeting on Language Acquisition, Universidade de Lisboa, 1 June.

Gavarró, A. and J. Solà. 2004b. Subextraction in Romance interrogatives. Going Romance 2004, Leiden University, 12 April.

Gavruseva, E. and R. Thornton. 2001. Getting it right: acquisition of whosequestions in child English. Language Acquisition, 9(3), 229-267. 
Grohman, K.K. 2011. Some Directions for the Systematic Investigation of the Acquisition of Cypriot Greek: A New Perspective on Production Abilities from Object Clitic Placement. In E. Rinke and T. Kupisch, eds. The Development of Grammar: Language Acquisition and Diachronic Change - Volume in Honor of Jürgen M. Meisel. (Hamburg Series on Multilingualism 11.) Amsterdam: John Benjamins, 179-203.

Grohmann, K.K., P. Panagiotidis and S. Tsiplakou . 2006. Properties of Wh-Question Formation in Cypriot Greek. 2nd International Conference on Modern Greek Dialects and Linguistic Theory, University of Patras, Mytilene, 30 September-3 October 2004.

Grohmann, K.K. and E. Papadopoulou. to appear. Question(able) Issues in Cypriot Greek. Linguistic Analysis, 37, 1-31.

Heck, F. 2008. On Pied-piping. Wh-movement and Beyond. Berlin: Mouton de Gruyter.

Horrocks, G. and M. Stavrou. 1987. Bounding Theory and Greek syntax: Evidence for wh-movement in NP. Journal of Linguistics. 23, 79-108.

Kayne, R. 2002. On some preposition that look like DP internal: English 'of' and French 'de', Ms., NYU.

Mathieu, E. 2002. The Syntax of Non-Canonical Quantification: A comparative Study. University College London: Doctoral Dissertation.

Mathieu, E. and I. Sitaridou. 2005. Split WH-constructions in Classical and Modern Greek: A diachronic perspective. In M. Batllori, M-L. Hermanz, C. Picallo and F. Roca, eds. Grammaticalization and parametric change. Oxford Scholarship Online, Oxford, 236-250.

Newton, B. 1972. Cypriot Greek: Its Phonology and Inflections. The Hague: Mouton.

Nomura, M. and K. Hirotsu. 2005. The Left Branch Condition in the Acquisition of Japanese. In M. Nomura, F. Niinuma and L. Reglero, eds. University of Connecticut working papers in linguistics, 13, 119-144.

Papadopoulou, E. 2013. The acquisition of wh-questions: Evidence from Cypriot Greek. Phd Dissertation, University of Essex.

Papadopoulou, E. and N. Pavlou. 2012. What I say, you say! Illustration of syntactic priming in Cypriot Greek. In K.K. Grohmann, A. Shelkovaya, and D. Zoumbalides 
(eds.). Linguists of Tomorrow: Selected Papers from the 1st Cyprus Postgraduate Conference in Theoretical and Applied Linguistics. Newcastle upon Tyne: Cambridge Scholars Publishing. [expected publication: late 2011/early 2012].

Pavlou, N. 2010a. Mbu! On wh-objects and true adjuncts of Cypriot Greek. 4th International Conference on Modern Greek Dialects and Linguistic Theory, University of Patras, Patra, 11-14 June 2009.

Pavlou, N. 2010b. Inda mbu, nambu or ine ti pu? Acquiring Complex Structures in Cypriot Greek. The ISCA Tutorial and Research Workshop on Experimental Linguistics, ISCA \& University of Athens, Athens, 25-27 August.

Pavlou, N. 2012. Pied-piping in wh-questions. What do children say about it? MA dissertation, University of York.

Roeper, T. and A. Pérez-Leroux. 1997. The interpretation of bare nouns in semantics and syntax: inherent possessive, pied piping, and root infinitives. MIT Occasional Papers in Linguistics 12. MA: MIT Press.

Ross, J. 1967. Constraints on variables in syntax. Doctoral dissertation, MIT

Schaeffer, J. 1991. The Italian child C-system. Ms. University of Venezia.

Stavrakaki S. 2006. Developmental perspectives on Specific Language Impairment: Evidence from the production of wh-questions by Greek SLI children over time. Advances in Speech-Language Pathology, 8, 384-396.

Thornton, R. and E. Gavruseva. 1996. Children's split "Whose-questions" and the structure of possessive NPs. Unpublished paper presented at the 21st Annual Boston University Conference on Language Development, Boston, United States.

van Kampen, J. 1994. The learnability of the Left Branch Condition. In R. BokBennema and C. Cremers, eds. Linguistics in the Netherlands 1994. 83-94. Amsterdam: John Benjamins.

van Kampen, J. 1996. PF/LF convergence in acquisition. In K. Kusumoto, ed. Proceedings of the NELS 26, 149-163.

van Kampen, J. 1997. First Steps in Wh-movement. Delft: Eburon. 